\title{
Applications of Computational Fluid Dynamics in Fish and Habitat Studies
}

\begin{abstract}
Computational fluid dynamics (CFD) is defined as a branch of fluid mechanics that solves fluid flow problems using numerical algorithms and methods. Using CFD to model water and contaminants transport in rivers, lakes, and coastal areas can significantly improve our understanding to manage these hydrodynamic systems. In this paper, 111 studies have been reviewed on different aspects of CFD application in ecohydrology that include: flow simulation and pressure distribution, sediment transport, hyporheic zone, fish habitat and temperature distribution. In general, three-dimensional models are reported to be more capable than twodimensional models to predict flow features and have been used more recently due to their ability to capture secondary flow. Two-dimensional models with secondary flow correction terms are acceptable and are being used as well. Discretization techniques and turbulence closures are also reported with comparisons. In general, majority of the studies were focused on flow and sediment transport; however, our knowledge about temperature distributions in nearbed regions and pool-riffle structures is limited and can be the subject of future studies.
\end{abstract}

Keywords: Flow simulation; Pressure distribution; Sediment transport; Hyporheic region; Fish habitat; Temperature 


\section{Introduction}

The hydrological cycle, which describes the transfer of water through the atmosphere, across the Earth's surface, and through the lithosphere, is a fundamental component of ecohydrology. Ecohydrology is an interdisciplinary field that focuses on the effects of hydrological processes on ecosystems and the effects of biotic processes on the hydrological cycle (Zalewski et al., 1997; Hannah et al., 2004). Furthermore, both physical (e.g. flow velocity) and structural (e.g. riverbed) variations within waterbodies impact aquatic ecosystems (Leclerc, 2005). Therefore, understanding how these variations change throughout a region is necessary for ecohydrological evaluation of river systems. In particular, streamflow is considered as the Master Variable (Karr 1991; Poff et al 1997) for riverine systems; therefore, both experimental and numerical approaches have been used to describe the relevance of streamflow to aquatic ecosystems (Sawyer et al., 2012; Plymesser and Cahoon, 2013). However, in general, numerical modeling is preferred over experimental approaches for several reasons, including lower development cost, faster execution time, and transferability to different regions (Papanicolaou et al., 2008; Abouali and Castillo, 2013).

Computational Fluid Dynamic (CFD) methods are numerical based approaches that solve flow equations to obtain velocity, pressure, and temperature distributions (Lane et al., 1999). This makes CFD an ideal tool for ecohydrologists, allowing them to better understand how flow patterns within environments interact with aquatic ecosystems. This study aims to synthesize the existing body of knowledge concerning the application of CFD in fish and habitat studies. The paper was organized into three sections: 1) introduction of CFD and its governing equations, 2) presentation of recent applications of CFD in ecohydrology, and 3) identification of knowledge gaps and possible future works.

\subsection{Governing Equations}

In a system, which is characterized and controlled by moving fluid, pressure and velocity distributions can be estimated using CFD methods. In particular, CFD is used to solve the conservation of mass and conservation of momentum. Conservation of mass states that the rate of mass change in a given system must be in balance with the rate of mass entering and leaving that system. For incompressible flows, the conservation of mass can be presented as follows:

$\frac{\partial u_{i}}{\partial \mathrm{x}_{i}}=0$

where, $u$, and $x$ represent flow velocity and direction, respectively.

Conservation of momentum states that the rate of linear momentum change of a given system is in balance with external forces. The conservation of momentum equation for a viscous fluid is called the Navier-Stokes equation and for Newtonian incompressible flows (such as water) is as follows: 
$\frac{\partial u_{i}}{\partial t}+u_{j} \frac{\partial u_{i}}{\partial \mathrm{x}_{j}}=-\frac{1}{\rho} \frac{\partial \mathrm{P}}{\partial x_{i}}+v \frac{\partial}{\partial x_{j}}\left(\frac{\partial u_{i}}{\partial \mathrm{x}_{j}}\right)+f_{i}$

where, $\rho, v$, and $P$ are fluid density, kinematic viscosity, and pressure respectively. The body forces (e.g. gravity) are described by the term $f$. Depending on the dimensions of study, $i$ can range from 1 to 3 (Versteeg and Malalasekera, 2007).

\subsection{Turbulent flow}

The governing equations 1 and 2 are valid to determine the pressure and velocity distributions in laminar flows; however, for turbulent flows, additional terms are needed to capture fluctuations as follows:

$u_{i}=\bar{u}_{\imath}+u_{i}^{\prime}$

$P=\bar{P}+P^{\prime}$

where, $\bar{u}_{\imath}$ and $\bar{P}$ are the average flow velocity and pressure and $u_{i}^{\prime}$ and $P^{\prime}$ are the flow velocity and pressure fluctuation terms, respectively.

In order to solve turbulent flow terms, two general approaches have been used: 1) turbulent flow simulation and 2) turbulent flow modeling (Pope, 2000).

\subsubsection{Turbulent flow simulation}

Turbulent flow simulation approaches solve the coupled equations (conservation of mass and momentum) for time-dependent velocities (with turbulent effects) for a given time period (Pope, 2000). One such approach is the Direct Numerical Simulation (DNS), in which all spatial and temporal ranges of turbulence flow need to be resolved (Orszag, 1970). However, the computation cost of DNS is proportional to the third power of the Reynolds number $\left(\propto \operatorname{Re}^{3}\right)$, which makes it difficult to use DNS for many applications (Pope, 2000). As a result, this approach is limited in its applications and is often only used for basic fundamental research (Moin and Mahesh, 1998).

Large Eddy Simulation (LES) is a more recent approach that divides turbulent motion into large and small scale eddies using a space filter function (Smagorinsky, 1963). In fully developed turbulent flow, the energy transfers from larger to smaller eddies through the concept called energy cascade. Large scale turbulent eddy motions, that are affected by boundary conditions, can be directly simulated. While for small scale in which eddies are relatively independent from boundary conditions, the turbulence flow should be modeled. Filtering large and small scale eddies in LES are accomplished by solving equation 5:

$\bar{\varphi}_{i}(\vec{x})=\int G(\vec{x}-\vec{\delta}) \varphi(\vec{\delta}) d \vec{\delta}$ 
where, $G$ is the filter convolution kernel that differentiates between small scale variations (fluctuations) and the large scale flow movements based on a defined threshold. As a result, $\varphi$ (e.g. velocity or pressure) will be decomposed into large scale $\left(\bar{\varphi}_{i}\right)$ and sub-grid scale $\left(\varphi_{i}^{\prime}\right)$ parts as follows (Pope, 2000; Sagaut, 2006):

$\varphi_{i}=\bar{\varphi}_{i}+\varphi_{i}^{\prime}$

\subsubsection{Turbulent flow modeling}

For turbulent flow modeling, governing equations are averaged to get the mean pressure and velocity distributions. By combining Equations 1 through 4, the Reynolds Averaged NavierStokes (RANS) equations can be derived for incompressible Newtonian fluid flows as follows (Hinze, 1975):

$\frac{\partial \overline{\mathrm{u}}_{i}}{\partial \mathrm{x}_{i}}=0$

$\rho \frac{\partial \bar{u}_{i}}{\partial t}+\rho \bar{u}_{j} \frac{\partial \bar{u}_{i}}{\partial \mathrm{x}_{j}}=-\frac{\partial \bar{P}}{\partial x_{i}}+\frac{\partial}{\partial x_{j}}\left[\mu\left(\frac{\partial \bar{u}_{i}}{\partial \mathrm{x}_{j}}+\frac{\partial \bar{u}_{j}}{\partial \mathrm{x}_{i}}\right)\right]+\frac{\partial \tau_{i j}}{\partial x_{j}}+f_{i}$

where, $\tau$ is the Reynolds stress tensor representing the turbulence effect on fluid flow and is defined as follows (Bates et al., 2005):

$\tau_{i j}=-\rho \overline{u_{\imath}^{\prime} u_{\jmath}^{\prime}}$

Turbulence models also known as closure models have been developed to estimate the Reynolds stress term $\left(\tau_{i j}\right)$ that is used to solve Equations 7 and 8.

Turbulent models can be divided into two main groups (Pope, 2000): 1) turbulent viscosity models; and 2) Reynolds stress models (RSMs).

Turbulent viscosity models obtain Reynolds stress values from turbulent viscosity by solving algebraic or two-equation models. However, in ecohydrology, the two-equation models are commonly used to account for convection and diffusion terms in turbulent systems. The $k-\varepsilon$ model (Launder and Spalding, 1972) is an example of the two-equation model in which the first variable, $k$, is used to define the turbulent kinetic energy while the second variable, $\varepsilon$, represents the turbulent dissipation.

The linear renormalization group (RNG) $k-\varepsilon$ model (Yakhot and Orszag, 1986) was modified from the standard $k-\varepsilon$. The RNG model is widely used in computational hydraulics due to the fact that it better performs in separation zones and under high shear conditions. Compared to the standard $k-\varepsilon$, the $\varepsilon$ equation in the RNG is modified to account for the different scales of motion by changing the production term. Both standard and RNG $k-\varepsilon$ closures assume isotropic viscosity. However, the standard $k-\varepsilon$ does not perform well for some complex conditions such as separated flows and flows in curved geometries (Bradshaw et al., 1981; Versteeg and Malalasekera, 2007) due to its semi-empirical nature. 
The $k-\omega$ turbulence closure (Wilcox, 1991) is another two-equation model, which has demonstrated to work well for separated flows with adverse pressure gradients (Yoon and Patel, 1996).

In contrast to $k-\varepsilon$ and RNG, which consider turbulent dissipation, the two-equation $k-\omega$ model considers the turbulent frequency $(\omega)$ effect. This allows the $k-\omega$ model to switch from a wall function to a low-Reynolds number formulation based on grid spacing. As a result, it is more accurate near walls compares to $k-\varepsilon$ and RNG. The $k-\omega$ closure is acceptable for wallbounded boundary layer, free shear, and low Reynolds number flows while it can also be used for complex boundary layer flows under adverse pressure gradients. For a very fine mesh resolution (Section 1.4), it is also able to predict flow separation in transitional flow problems.

In contrast to turbulent viscosity models, RSMs are second-order closure that use transport equations instead of turbulent viscosity to provide Reynolds stress values and dissipation rates (Pope, 2000). Meanwhile, RSMs require modeling of dissipation rate, pressure rate of strain, and Reynolds stress flux resulting in more complex formulation, higher computational cost, and convergence issues compared to two-equation turbulent viscosity models (Rodi, 1993; Pope, 2000).

\subsection{Depth-averaged equations}

For unidirectional flows, such as shallow water for which vertical flow variation is negligible, two dimensional depth-averaged equations are preferred compared to the full three dimensional approaches. In the depth-averaged equations, the longitudinal and traverse velocities in Cartesian system are defined as follows (Bates et al., 2005):

$\bar{u}_{\iota}=\frac{1}{h} \int_{0}^{h} u_{i} d z \quad ; \quad(i=1,2)$

where, $z$ is the vertical axis.

Using Equation 10, the depth-averaged Navier-Stokes (DANS) equations are developed as follows (Bates et al., 2005):

$\frac{\partial h}{\partial t}+\frac{\partial}{\partial x_{i}}\left(h \bar{u}_{l}\right)=0$

$\rho \frac{\partial \overline{u_{l}}}{\partial t}+\rho \frac{\partial\left(\overline{u_{\imath} \bar{u}_{\jmath}}\right)}{\partial \mathrm{x}_{j}}=-\rho g_{i} \frac{\partial h}{\partial x_{i}}+\frac{\partial \tau_{i j}}{\partial x_{j}}+\frac{\tau_{i}^{s}-\tau_{i}^{b}}{h}+\frac{1}{h} \frac{\partial}{\partial x_{j}}\left(\int_{0}^{h} \rho\left(u_{i}-\overline{u_{\imath}}\right)\left(u_{j}-\overline{u_{J}}\right) d z\right)$

Equation 12 introduces two new stress/dispersion terms $\left(\tau_{i}{ }^{s}\right.$ and $\left.\tau_{i}{ }^{b}\right)$ that represent surface and bed stresses, respectively. 
It is important $\mathrm{t}$ to note that turbulent closure models are required to solve DANS that have been derived from RANS (Pope, 2000).

\subsection{Discretization methods:}

The Navier-Stokes equations cannot be solved directly; therefore, discretization techniques are used. Three common discretization techniques are: 1) finite-difference method (FDM); 2) finite element method (FEM); and 3) finite volume method (FVM). FDM is the oldest technique that applies a local Taylor expansion to approximate the differential equations at different nodes (Smith, 1985). While FEM and FVM divide the system into areas with boundary values instead of nodes. The FEM approach simplifies governing equations to a set of simple equations that can be easily calculated for each area. These equations can then be summed to calculate the value for the desired parameter (e.g. velocity) (Burnett, 1987). Meanwhile, FVM uses Gauss's theorem to calculate the desired parameters and relate flow variation in a domain to input and output flows (Ramadhyani and Patankar, 1980; Versteeg, H.K., Malalasekera, W., 2007). Despite the grid differences, FVM and FEM equation systems are almost the same, and the equivalent FVM system can be obtained from FEM (Mattiussi, 1997).

\section{Discussion}

\subsection{Flow and sediment transport}

The majority of CFD applications in the riverine ecosystem modeling are focused on streamflow and sediment transport. Developed models include two-dimensional (2D) models such as SERATRA (Onishi and Wise, 1982), TABS-2 (Thomas and McAnally, 1985), MIKE 21 (Danish Hydraulic Institute, 1993) and FAST2D (Minh Duc et al., 1998), and three-dimensional (3D) models such as RMA-10 (King, 1988), SSIM (Olsen, 1994), EFDC (Hamrick, 1996), FAST3D (Landsberg et al., 1998), Delft3D (Delft Hydraulics, 1999), and TELEMAC (Hervouet and Bates, 2000). Two-dimensional models usually solve DANS equations, while RANS have been widely used for 3D models. In general, development of 3D models is more challenging than 2D for defining boundary conditions (Lane et al., 1995, 1998). However, 3D models are able to provide more details on complex riverine ecosystem problems such as flows with separation or secondary flow currents (Wu et al., 2000; Ruther and Olsen, 2005; Fischer-Antze et al., 2008; Papanicolaou et al., 2008).

In terms of the turbulence model selection, standard $k-\varepsilon$ is the most commonly used model for flow and sediment transport due to its simplicity. However, comparing to RNG models, $k-\varepsilon$ underestimates both flow separation zone and number of vortices in 3D sediment transport studies. In addition, RNG provides more accurate predictions especially in highly sinuous streams (Dargahi, 2004; Rodrigez et al., 2004).

Among aforementioned models, SSIIM (Olsen, 1994) has been widely used for fish and habitat studies when sediment is an influential factor (Booker, 2003; Wang and Chao, 2011). SSIIM is a 
3D FVM model that solves RANS equations with the $k-\varepsilon$ turbulence model (Olsen, 1994). This model also uses an experimental formula presented by Van Rijn (1984) for sediment transport and is able to simulate both bed and suspended loads (Papanicolaou et al., 2008). Comparison of two 3D SSIIM and TELEMAC models against experimental data revealed that both models are reliable for hydraulic and morphologic applications while SSIIM performed better on bended channels (Hervouet, 2000; Riesterer,et al., 2013).

\subsection{Fish and Habitat Studies}

From an ecological point of view, fish communities are highly influenced by instream flow pattern and channel morphology variation (Frothingham, 2001). Some simple/small scale studies have revealed the importance of these variations on biological activities in aquatic ecosystems (Cullen, 1991; Hayes and Jowett, 1994; Fischenich and Seal, 1999; Crowder and Diplas, 2006). Meanwhile, in recent years, CFD has been widely used in riverine studies to reveal the more complex/large scale impacts of flow variation in engineered rivers (Booker, 2003; Rodriguez et al., 2004; Kolden et al., 2016), fish passages (Khan, 2006; Cea et al., 2007; Feurich et al., 2012; Haro et al., 2015), and submerged barriers (Shen and Diplas, 2008; Constantinescu et al., 2013; Baki et al., 2015).

\subsubsection{Engineered river channels}

Instream hydrodynamic variability plays a key role on habitat abundance and variability of species; in particular, these effects are amplified in engineered compared to natural rivers (Lipcius et al., 1997). To address these issues, Booker (2003) used SSIIM to simulate fish habitats in two engineered rivers (with different modification levels) during high flows. Two major simplification assumptions were made in this study: (1) upstream flow was uniform, and (2) a wall law was used to model velocity pattern near the wall. These were reported to not significantly affect the velocity profile. This study concluded that within more modified river systems (urban), fewer habitats can exist while refugia for fish became more limited. It also revealed the importance of physical habitat on fish survival in urban rivers; especially during the high peak (Booker, 2003). A grid dependency analysis was also performed in order to quantify the effect of grid resolution on velocity estimation. Interestingly, the order of uncertainty caused by change in grid resolution is the same as the measurement errors and even less than the uncertainty level of habit indices like maximum sustainable swimming speed (Booker, 2003). A year later, Rodriguez et al. (2004) applied the 2D STEREM model (Bernard, 1993) and a commercial 3D model called FLOW-3D ${ }^{\circledR}$ to simulate flow through a highly sinuous river (FLOW-3D, 2016). The results were verified with high quality 3D velocity data collected from the Embarrass River in central Illinois. DANS and RANS equations were used for 2D and 3D modeling, respectively. Comparison of observed and simulated results showed that the 3D model using RNG turbulence closure provided a reliable flow prediction and can capture separation zones, while for the 2D modeling, secondary flow correction should be applied to provide reliable predictions (Rodrigez et al., 2004). In terms of biological evaluation, they found 
meandering pools had high velocity core flow, which limits the pools' functionality as refuge for fish species (Rodrigez et al., 2004).

Kolden et al (2016) also used FLOW-3D to evaluate fish habitats in Whitewater parks (WWPs) and natural pools in the Colorado River. The results proved that 3D modeling provides more accurate flow pattern than 2D models. They calculated depth, depth-averaged velocity, turbulent kinetic energy, and 2D and 3D vorticities and found that all of these hydraulic measures were higher in WWP pools than natural pools (Kolden et al., 2016). In terms of fish habitat, more abundance was observed in natural pools than WWP pools, which suggested a correlation between hydraulic measures (such as turbulent kinetic energy), 2D and 3D vortices, and fish abundance. However, additional research would be required to reveal these correlations (Kolden et al., 2016).

\subsubsection{Fish passages}

CFD has been used to evaluate the response of fish habitats to flow rate change and barriers in their way. An early version of CFD tools developed for evaluation of habitat passages is called River2D that was developed by the University of Alberta (River2D, 2015). This two dimensional software uses a depth-averaged hydrodynamic model that solves DANS equations with FEM discretization (Steffler and Blackburn, 2002). Haro et al. (2012) used River2D to develop the CFD-Habitat Suitability Index (CFD-HSI) model to predict possible fish passage struggles due to shallow depth and high velocity flows that could result from dam removal. The suitability index was compromise of fish length, fish body shape, cruising swimming speed, and maximum swimming speed (Haro et al., 2015). CFD-HSI was applied to evaluate dam removal effects on fish passage at three rivers with low $\left(\sim 100 \mathrm{~m}^{3} / \mathrm{sec}\right)$, normal $\left(\sim 345 \mathrm{~m}^{3} / \mathrm{sec}\right)$, and high $(\sim 790$

$\mathrm{m}^{3} / \mathrm{sec}$ ) flow rates. They found that velocity and depth are two key parameters affecting fish passage and any alteration of these two parameters creates challenge zones for fish (Haro et al., 2015). They also found that rise in flow rate increases the potential challenge zones size and number, which in turn made the passage more difficult for fish (Haro et al., 2015).

Besides dams, another anthropogenic obstacle that impacts fish passage are culverts, which are generally designed to optimize the hydraulic efficiency of the river with little attention to fish passage (Baker and Votapka, 1990; Blakely et al., 2006; Feurich et al., 2012). Several solutions such as weir baffle, slotted weir, or spoiler baffles are being used to make fish passage easier in culverts. Among those, spoiler baffles are easy to install and efficient for fish sizes of 50-70 mm (Feurich et al., 2012). Feurich et al. (2012) used FLOW-3D to assess the impact of spoiler baffle size and arrangement on their performance. For this purpose, they solved RANS equations with the RNG $k-\varepsilon$ turbulence model that was known to perform better in complex flows than the standard $k-\varepsilon$ (Feurich et al., 2012). Using four different flow rates in a $1.3 \mathrm{~m}$ culvert along with four baffle sizes, they found that larger spoiler baffles are more efficient for fish passage while normal size spoilers provide suitable fish passage for small fish (less than $10 \mathrm{~cm}$ long) (Feurich et al., 2012). 
Vertical Slot Fishways (VSF), that let fish swim upstream have also been used to ease fish migration between pools. If designed correctly, an effective fishway should let fish enter, pass through, and exit safely with minimum time and energy (Bermudez et al., 2010). Using 2-D depth-averaged shallow water equations coupled with $k-\varepsilon$ turbulence model, Bermudez et al. (2010) showed that the length of the pool is the most important geometric parameter affecting fishway biological efficiency. Width of the slot and width of the pool have less impact on flow characteristics. They also found that flow pattern, average velocity in the slot, discharge curve, and turbulence can be used for evaluation of biological efficiency.

Cea et al. (2007) applied three turbulence models with a 2-D depth averaged shallow water model to find a suitable model for flow pattern and turbulent field prediction within vertical slots. (Cea et al., 2007). They also used a finite volume solver with three turbulence closure models including the mixing length, $k-\varepsilon$, and an algebraic stress model. Among those, the latter two were better predictors of experimental velocity field and water depth field measurements, and the $k-\varepsilon$ made better predictions for water depth field (Cea et al., 2007). The mixing length model performed worse and was reported to be more sensitive to the total discharge. Both the $k-\varepsilon$ and algebraic stress models were reported to agree with experimental results, although the algebraic stress model was slightly better in predicting turbulent kinetic energy (Cea et al., 2007).

Three-dimensional models have also been used for fishway modeling in parallel, however did not consider free surface effects (Lai et al., 2003; Khan et al., 2004). Khan (2006) developed a 3D CFD model that considers free surface. Using the commercial FLUENT software, Khan (2006) included the finite volume method and solved RANS equation with the $k-\varepsilon$ turbulence model. The model was able to determine velocities and drag forces that impacts fish migrating upstream. In addition, the results showed that higher velocities would occur just behind the vertical slots where the largest change in free surface exists (Khan, 2006).

\subsubsection{Submerged barriers}

Submerged barriers such as vegetation, freshwater muscles, or boulders impact fish habitats. In addition, aquatic vegetation has been found to have significant impacts on water current and transmission volume of hydraulic power. Using numerical modeling to estimate these impacts on flow is well studied in CFD (Kutija and Hong, 1996; Fischer-Antze et al., 2001; Wilson et al., 2006). Two major approaches have been commonly used for showing submerged vegetation effects on flow: (1) adding a drag force that considers resistance in the flow caused by vegetation, and (2) enhancing the roughness coefficient (Chao, 2001; Jarvela, 2005; Chao et al., 2009). However, none considered flexibility of submerged vegetation and consider them as a solid immobile body, while in reality, vegetation bends with flow. This results in various changes in the flow pattern, which is contrary to the previously mentioned simple assumptions. To answer this question, Wang and Chao (2011) surveyed the physical and biological 
characteristics of the Nansi Lake in China to determine expressions and parameters to evaluate the hydraulic resistance caused by emergent and submerged vegetation. These values were then used to develop a SSIIM model for predicting velocity components and flow filed in the Nansi Lake. A comparison between the simplified method of assigning a high roughness coefficient to the lake bed and the new approach showed that the calculation error between simulated flow and field observed data were less than $15 \%$ for the new approach, while those errors were up to $35 \%$ using the simplified approach.

Aquatic organisms (e.g. freshwater mussels) living at the sediment-water interface are also sensitive to physical changes such as flow velocity, depth, bed material, and nutrient variation in the stream (Constantinescu et al., 2013). Freshwater mussels play an important role in maintaining ecological integrity of lotic ecosystems. Several spatial scales of study need to be considered to investigate freshwater mussel habitats, including (a) basin, (b) habitat, and (c) mussel scales. The mussel scale is appropriate to investigate physical characteristics surrounding mussels, including local momentum, mass transport, and bed change (Constantinescu et al., 2013).

Here again, numerical simulations can be used for flow field, sediment and nutrient transport studies focused on freshwater mussels under user-defined orientations. Numerical modeling is able to evaluate mussels' stability by calculating shear stress and drag forces they face. Recently, Constantinescu et al., (2013) used large-eddy simulation (LES) to simulate stream flow, transport structures, and bed shear stress around a cluster of three half-buried mussels at vertical standing. They used data from Particle Image Velocimetry (PIV) laboratory experiments with the same geometry to validate these results.

In studies of large scale flow passing around large scale bodies, LES is preferred to the RANS equation due to its higher accuracy (Rodi, 1997; Keylock et al., 2005). LES is a useful tool to reveal flow patterns in regions with hard to obtain measurements or those subject to high measurement error, because it provides the entire flow field simulation. The LES code, which is applied in Constantinescu et al., (2013) study, uses a collocated finite-volume scheme to solve the filtered Navier-Stokes equations with the dynamic Smagorinsky model. The successive over relaxation (SOR) method was used to solve discretized governing equations. No wall functions were used, and the governing equations were integrated through the viscous sub-layer. The code was capable of using unstructured hybrid meshes as well (Constantinescu et al., 2013). Results showed that the LES model is able to detect the formation, location, shape, and coherence of the vortices generated near the upstream face of mussels with detailed information. Computed values agreed with PIV measurements. It also showed agreement with some previous studies on flow passing around bluff bodies. The shear stress was found highly dependent on the main necklace vortex and the acceleration of the flow passing the edges of mussels (Constantinescu et al., 
2013). Momentum and mass transport around these mussels was also found to be a function of bed shear stress and vertical content of the flow field (Constantinescu et al., 2013).

CFD has been also used to study the impact of boulders on flow patterns (Shen and Diplas, 2008; Oertel and Schlenkhoff, 2012; Baki et al., 2016). Shen and Diplas (2008) used RMA2 (Thomas and McAnally, 1985), a steady-state 2D model, and a commercial 3D hydrodynamic model named ANSYS-CFX, that solves the steady-state RANS equations with FVM, to find flow pattern alterations around submerged boulders. RSM was used for turbulent closure, and circulation and vorticity concepts were employed to define flow patterns created behind boulders, which can be used as refugia by fish and invertebrates (Shen and Diplas, 2008). The RSM used in Shen and Diplas (2008) study was a simplified version of the formulation introduced by Launder et al. (1975) and did not include wall-reflection terms. However, they found that the 3D model using RSM, can detect spatial flow feature variations (e.g. reverse velocity and predominant circulations) more accurately than the $2 \mathrm{D}$ model, using zero-equation model. Knowing the advantages of 3D models in boulder studies, Baki et al. (2016) used the same 3D software (ANSYS-CFX) with $k-\varepsilon$ turbulence model to evaluate role of several parameters including flow rate, channel slope, boulder size, spacing, and pattern on water depth and velocity that impact fish passage. They provided a guideline for boulder design by developing a model that related velocity and depth variations to discharge and boulder density under different scenarios. Based on the results, they recommended boulder spacing for two patterns of isolated and clustered that met required flow velocity and depth for natural fish passage (Baki et al., 2016).

\subsection{Hyporheic and Interface Exchange Zone}

Some recent numerical studies have been done on the hyporheic exchange zone, interfacial exchange zone, and sediment water interface, which are the host of many biochemical processes. Tonina and Buffington (2007) used FLUENT to simulate hyporheic exchange in a gravel poolriffle channel. They used a 3D finite element grid and solved the Darcy equation for groundwater flow and improved the 2D hyporheic exchange model developed by Elliot and Brooks (1997). Results showed that the 3D model was able to capture features (e.g., near bed pressure profile variation) not observed in the $2 \mathrm{D}$ model. In addition, this study revealed that not only the bed form amplitude, but also discharge and bed form interaction affects the magnitude and pattern of the hyporheic exchange zone (Tonina and Buffington, 2007).

Cardenas and Wilson (2007) used CFD to investigate interaction of turbulent water-column flow, topography driven flow in permeable sediments, and groundwater discharge from and to deep groundwater. For this purpose, a Darcian model of pore-water flow and 2D steady-state RANS equations with the $k-\omega$ turbulence closure were solved, using the commercial CFD-ACE+ code. Their results showed that interaction of forces generated by current-bed form and groundwater discharge impact the shape and depth of the interfacial exchange zone (Cardenas and Wilson, 2007). They also defined the critical water-column Reynolds number, which for 
values below it, fluid flow through the sediment will be dominated by ambient groundwater discharge and only one dimensional flow (upward or downward) will occur (Cardenas and Wilson, 2007).

The hyporheic exchange zone can also be affected by large woody debris that play an important role in macroinvertebrate and fish habitats (Angermeier and Karr, 1984; Wallace et al., 1995; Abbe and Montgomery, 1996; Wright and Flecker, 2004). Sawyer et al. (2011) developed Cardenas and Wilson's (2007) model to include bed pressure profile and hyporheic exchange rates near the channel-spanning log that can be used to evaluate the impact of large woody debris removal or reintroduction in hyporheic mixing. In contrast to Cardenas and Wilson (2007), who represented the free surface as a slip boundary, here the free surface was also included in flow simulation, due to its variation caused by channel spanning logs. Their results showed removal of large woody debris will drastically reduce the hyporheic exchange zone and it will be more significant for straight channels with simple morphology. As a result, aquatic habitat and hydrologic connectivity will be affected (Sawyer et al., 2011).

\subsection{Heat Transfer studies}

CFD can also be used to solve temperature distribution equations. Many thermal issues exist in lotic and lentic environments and CFD methods can be used to model and predict them. For example, 2D and 3D numerical simulations of heat pollution caused by condenser cooling water draining to water bodies. Ozturk et al. (1995) and Duan et al. (2008) used 2D simulation to find the velocity field and temperature distribution where thermal effluent is discharged. A quasi 3-D model that simulates the thermal impact of warm water discharges in rivers was also developed by Dinelli et al. (1979), assuming buoyancy forces are negligible. Some 3D models have been also developed, such as the surface water model by Hamrick and Mills (2000), which considers thermal transport, eutrophication, toxic contamination and fate in free surface waterbodies. Wu et al. (2009) predicted temperature distribution in a lake due to the thermal discharge. They used FLUENT and implemented FVM to solve the governing equations with no-slip conditions and zero heat flux on all walls as boundary conditions. The results showed that the thermal influence area was limited (in the range of $50 \mathrm{~m}$ nearby the discharge inlet). They also found that the water temperature can recover in just one hour after thermal discharge stops (Wu et al., 2009).

Recent numerical simulations have been done to explore temperature distribution in permeable sediments and the hyporheic zone. Permeable sediments host numerous riverine biological processes (Stanford and Ward, 1988; Boulton et al., 1998; Hancock et al., 2005), many of which are temperature dependent varying on daily cycles that impact the water column and water chemistry (Westrich and Berner, 1988; Nimick et al., 2003; Cardenas and Wilson, 2007). In the hyporheic zone, temperature is a crucial parameter affecting microbial activity, invertebrate development, and survival (Brunke and Gonser, 1997; Brown et al., 2004; Sawyer et al., 2012). Temperature also plays an important role in spawning site selection and competitive behaviors in 
channel flows (Magnuson et al., 1979; De staso III and Rahel, 1994; Baxter and Hauer, 2000; Sawyer et al., 2012).

Cardenas and Wilson (2007) used coupled 2-D RANS equations with $k-\omega$ turbulence closure, Darcy-groundwater flow, and heat transport in the sediments equations to reveal the impact of topography driven flow on sediment dunes' thermal regime. Assuming that thermal forces on sediments are caused by temperature variations in the water column, they showed that in the absence of rapid flux exchange in the water column, conduction is the dominant form of heat transfer. Advection becomes important by increasing sediment permeability and flow velocity by generating more complex thermal patterns (Cardenas and Wilson, 2007). The global Peclet number depending on topography and thermal properties was used to evaluate the ratio of conduction to advection heat transfer. They also found that viscosity variation caused by thermal regime affects the flow pattern passing through sediments but has negligible effects on sediment temperature distribution (Cardenas and Wilson, 2007).

Sawyer et al. (2012) developed a model for the hyporheic zone to quantify flow and heat transfer caused by interactions of current with channel-spanning logs. Setting the pressure distribution at interface level to be the same for both porous and channel flows, coupled channel flow and hyporheic flow were simulated (Sawyer et al., 2011). Advection-conduction-dispersion equations linked heat and fluid flow and the steady state assumption was used for solving groundwater equations (Sawyer et al., 2012). Other simplifications included: homogeneous sediment, no groundwater discharge and simple large woody debris. Results showed how debris change thermal homogeneity at hyporheic zone. Blocking ratio, Froude number, and sediment permeability increase this impact. Among these factors, permeability showed the most variation in the river and the potential of having the greatest control on hyporheic flow and heat exchange (Sawyer et al., 2012).

Instream temperature variation is also known as a key factor in defining habitat suitable areas (Yao et al., 2014; 2015). So far, flow velocity and flow depth were used to allocate habitat suitable locations using the Habitat Suitability Index (HSI), while Yao et al. (2014) added temperature as driving force as well. Solving the DANS equation along with the heat transport equation and $k-\varepsilon$ turbulence closure were used to find the fish habitat level downstream of the Glen Canyon dam on the Colorado River (Yao et al., 2015). They also developed a habitat suitability equation that can be used for habitat condition simulation under high flow conditions. Yao et al. (2015) found that habitat suitability is highly dependent on dam operation and temperature variation is the key factor causing poor habitat suitability for low flow conditions.

\section{Conclusion}

This report summarizes CFD applications in four related areas of ecohydrology: flow field and sediment transport, fish and habitat, hyporheic and interface exchange zones, and heat transfer. 
Flow field and sediment transport simulations started in 1980s using Finite Difference Methods (FDMs). Finite Element Methods (FEMs) and Finite Volume Methods (FVMs) studies were applied later, with more recent studies using FVMs. 2D models generally used depth averaged equations while 3D models solved RANs equations and simulate the entire field. $k-\varepsilon$ was preferred to the other turbulence closure forms due to its simplicity. Comparison of 2D and 3D models showed that 3D models are able to capture secondary flow but require more complicated boundary conditions while more computationally expensive. The advantage of using 3D models was capturing secondary flow in complicated geometries, flow separation, and adverse pressure gradients. The summary of these studies are presented in the Appendix (Tables A1 and A2).

Flow pattern, bed change and morphology also influence riverine ecosystems. CFD has been used to predict response of aquatic species to these variations. Some studies were performed on fishways (e.g. vertical slots, pool and riffle structure). Finite volume 2D depth averaged or 3D RANS equations with $k-\varepsilon$ turbulence closure were used to find flow patterns in various geometries and relating that to species related indices like maximum sustainable swimming speed. A limited number of studies have been also done to determine the impact of vegetation, freshwater mussels and other barriers on streamflow and subsequent impact on stream habitat. Only one study was found to use Large Eddy Simulation (LES), a more detailed approach than RANS, where the authors found flow pattern and turbulence around three submerged freshwater mussels. Studies using more detailed geometries and dynamic barriers (submerged vegetation and small bodies) in flow are still needed. Regarding fishways, the role of pool-riffle structures and the dynamic response of the morphology change on streamflow and fishways can be future research.

Hyporheic zones are the host of several biological processes in river system. $k-\omega$ was preferred to $k-\varepsilon$ due to its better prediction of the adverse pressure gradients that exist in these regions. The 2D RANS approach was the most common form of equations used for hyporheic and interface exchange zones studies, showing the importance of large woody debris in the hyporheic zone. 3D simulations can be useful to capture more detailed features in the hyporheic zone.

Solving the energy equation in parallel with mass and momentum equations provides temperature distribution as well. Temperature variations exhibit significant control on aquatic integrity in hyporheic zones, interface exchange and sediment layers. A few studies were done to find temperature variations in these regions, but were limited to 2D. However, more 2D and 3D studies are done on heat pollution and its impact on waterbodies. Developing 3D LES models that provide more detailed temperature distributions in near-bed regions and pool-riffle structures can be future areas of research.

\section{Acknowledgment}


This work is supported by the USDA National Institute of Food and Agriculture, Hatch project MICL02212.

\section{References:}

Abbe, T.B., Montgomery, D.R., 1996. Large woody debris jams, channel hydraulics and habitat formation in large rivers. Regulated Rivers Research \& Management 12, 201-221.

Abouali, M., Castillo, J.E., 2013. Unified curvilinear ocean atmosphere model (ucoam): A vertical velocity case study. Mathematical and Computer Modelling 57, 2158-2168.

Angermeier, P.L., Karr, J.R., 1984. Relationships between woody debris and fish habitat in a small warmwater stream. Transactions of the American Fisheries society 113, 716-726.

ANSYS-CFX, 2003. CFX-5 Solver Theory, CFX Ltd. Didcot Oxfordshire, UK.

Baker, C.O., Votapka, F.E., 1990. Fish Passage Through Culverts. U.S. Forest Service.

Baki, A.B.M., Zhu, D.Z., Rajaratnam, N., 2016. Flow Simulation in a Rock-Ramp Fish Pass. Journal of Hydraulic Engineering 142, 4016031.

Bates, P.D., Lane, S.N., Ferguson, R.I. (Eds.), 2005. Front Matter, in: Computational Fluid Dynamics. John Wiley \& Sons, Ltd, pp. i-viii.

Baxter, C.V., Hauer, F.R., 2000. Geomorphology, hyporheic exchange, and selection of spawning habitat by bull trout (Salvelinus confluentus). Canadian Journal of Fisheries and Aquatic Sciences 57, 1470-1481.

Bermúdez, M., Puertas, J., Cea, L., Pena, L., Balairón, L., 2010. Influence of pool geometry on the biological efficiency of vertical slot fishways. Ecological Engineering 36, 1355-1364.

Bernard, R.S., 1993. STREMR: Numerical model for depth-averaged incompressible flow. DTIC Document.

Blakely, T.J., Harding, J.S., Mcintosh, A.R., Winterbourn, M.J., 2006. Barriers to the recovery of aquatic insect communities in urban streams. Freshwater Biology 51, 1634-1645.

Booker, D.J., 2003. Hydraulic modelling of fish habitat in urban rivers during high flows. Hydrol. Process. 17, 577-599.

Boulton, A.J., Findlay, S., Marmonier, P., Stanley, E.H., Valett, H.M., 1998. The functional significance of the hyporheic zone in streams and rivers. Annual Review of Ecology and Systematics 59-81.

Bradshaw, P., Cebeci, T., Whitelaw, J.H., 1981. Engineering calculation methods for turbulent flow. Academic Press.

Brown, J.H., Gillooly, J.F., Allen, A.P., Savage, V.M., West, G.B., 2004. Toward a metabolic theory of ecology. Ecology 85, 1771-1789. 
Brunke, M., Gonser, T.O.M., 1997. The ecological significance of exchange processes between rivers and groundwater. Freshwater biology 37, 1-33.

Burnett, D.S., 1987. Finite element analysis: from concepts to applications. Addison-Wesley Pub. Co.

Cardenas, M.B., Wilson, J.L., 2007. Dunes, turbulent eddies, and interfacial exchange with permeable sediments. Water Resour. Res. 43, W08412.

Cea, L., Pena, L., Puertas, J., Vázquez-Cendón, M.E., Peña, E., 2007. Application of several depthaveraged turbulence models to simulate flow in vertical slot fishways. Journal of Hydraulic Engineering 133, 160-172.

Chao, W., 2001. Modeling of water dynamics and pollutant spreading in the Luomahu reservoir for water transfer form South to North of China. Journal of Hydrodynamics, Ser. B 13, 14-23.

Chao, W., YU, J., WANG, P., GUO, P., 2009. Flow structure of partly vegetated open-channel flows with eelgrass. Journal of Hydrodynamics, Ser. B 21, 301-307.

Constantinescu, G., Miyawaki, S., Liao, Q., 2013. Flow and turbulence structure past a cluster of freshwater mussels. Journal of Hydraulic Engineering 139, 347-358.

Crowder, D.W., Diplas, P., 2006. Applying spatial hydraulic principles to quantify stream habitat. River Research and Applications 22, 79-89.

Cullen, R.T., 1991. Vortex mechanisms of local scour at model fishrocks, in: Fisheries Bioengineering Symposium: American Fisheries Society Symposium 10. p. 213.

Danish Hydraulic Institute. 1993. MIKE 21 short description, Danish Hydraulic Institute, Hørsholm, Denmark.

Dargahi, B., 2004. Three-dimensional flow modelling and sediment transport in the River Klarälven. Earth Surface Processes and Landforms 29, 821-852.

Delft Hydraulics, D., 1999. User Manual Delft3D-FLOW. The Netherlands.

De Staso III, J., Rahel, F.J., 1994. Influence of water temperature on interactions between juvenile Colorado River cutthroat trout and brook trout in a laboratory stream. Transactions of the American Fisheries Society 123, 289-297.

Dinelli, G., Castellano, L., 1979. Design Model for Thermal Effluent in Rivers. ASCE J Hydraul Div $105,197-211$.

Duan, M., Li, Z., Jiang, S., Shu, H., Zhu, Y., 2008. Numerical simulation of the thermal discharge in Xinghai bay seawater source heat pump project. Taiyangneng Xuebao/Acta Energiae Solaris Sinica 29, 832-836.

Elliott, A.H., Brooks, N.H., 1997. Transfer of nonsorbing solutes to a streambed with bed forms: Theory. Water Resources Research 33, 123-136.

Feurich, R., Boubée, J., Olsen, N.R.B., 2012. Improvement of fish passage in culverts using CFD. Ecological Engineering 47, 1-8. 
Fischenich, C., Seal, R., 1999. Boulder clusters. DTIC Document.

Fischer-Antze, T., Olsen, N.R.B., Gutknecht, D., 2008. Three-dimensional CFD modeling of morphological bed changes in the Danube River. Water Resour. Res. 44, W09422.

Fischer-Antze, T., Stoesser, T., Bates, P., Olsen, N.R.B., 2001. 3D numerical modelling of openchannel flow with submerged vegetation. Journal of Hydraulic Research 39, 303-310.

FLOW-3D, 2016. Flow Science. URL: https://www.flow3d.com/ (accessed 10.12.16).

Frothingham, K.M., 2001. Geomorphological processes in meandering and straight reaches of an agricultural stream in East Central Illinois: Relations to aquatic habitat. University of Illinois at Urbana-Champaign.

Hamrick, J.M., 1996. User's manual for the environmental fluid dynamics computer code. Department of Physical Sciences, School of Marine Science, Virginia Institute of Marine Science, College of William and Mary.

Hamrick, J.M., Mills, W.B., 2000. Analysis of water temperatures in Conowingo Pond as influenced by the Peach Bottom atomic power plant thermal discharge. Environmental Science \& Policy 3, 197-209.

Hannah, D.M., Wood, P.J., Sadler, J.P., 2004. Ecohydrology and hydroecology: A “new paradigm”? Hydrological processes 18, 3439-3445.

Hancock, P.J., Boulton, A.J., Humphreys, W.F., 2005. Aquifers and hyporheic zones: towards an ecological understanding of groundwater. Hydrogeology Journal 13, 98-111.

Haro, A., Chelminski, M., Dudley, R.W., 2015. Computational Fluid Dynamics-Habitat Suitability Index (CFD-HSI) Modelling as an Exploratory Tool for Assessing Passability of Riverine Migratory Challenge Zones for Fish. River Res. Applic. 31, 526-537.

Haro, A.J., Dudley, R.W., and Chelminski, M., 2012, Development of computational fluid dynamics - habitat suitability (CFD-HSI) models to identify potential passage - Challenge zones for migratory fishes in the Penobscot River: U.S. Geological Survey Fact Sheet 2012-3073.

Hayes, J.W., Jowett, I.G., 1994. Microhabitat models of large drift-feeding brown trout in three New Zealand rivers. North American journal of fisheries management 14, 710-725.

Hervouet, J.-M., 2000. TELEMAC modelling system: an overview. Hydrol. Process. 14, 2209-2210.

Hinze, J.O., 1975. Turbulence. McGraw-Hill, New York.

Järvelä, J., 2005. Effect of submerged flexible vegetation on flow structure and resistance. Journal of Hydrology 307, 233-241.

Karr, J.R., 1991. Biological integrity: A long-neglected aspect of water resource management. Ecological applications 1, 66-84. 
Keylock, C.J., Hardy, R.J., Parsons, D.R., Ferguson, R.I., Lane, S.N., Richards, K.S., 2005. The theoretical foundations and potential for large-eddy simulation (LES) in fluvial geomorphic and sedimentological research. Earth-Science Reviews 71, 271-304.

Khan, L.A., 2006. A three-dimensional computational fluid dynamics (CFD) model analysis of free surface hydrodynamics and fish passage energetics in a vertical-slot fishway. North American Journal of Fisheries Management 26, 255-267.

Khan, L.A., Wicklein, E.A., Rashid, M., Ebner, L.L., Richards, N.A., 2004. Computational fluid dynamics modeling of turbine intake hydraulics at a hydropower plant. Journal of Hydraulic Research 42, 61-69.

King, I.P., 1988. A finite element model for three dimensional hydrodynamic systems. Report prepared by Resource Management Associates, Lafayette California, for US Army Corps of Engineers, Waterways Experiment Station, Vicksburg, Mississippi.

Kolden, E., Fox, B.D., Bledsoe, B.P., Kondratieff, M.C., 2016. Modelling Whitewater Park Hydraulics and Fish Habitat in Colorado. River Res. Applic. 32, 1116-1127.

Kutija, V., Hong, H.T.M., 1996. A numerical model for assessing the additional resistance to flow introduced by flexible vegetation. Journal of Hydraulic Research 34, 99-114.

Lai, Y.G., Weber, L.J., Patel, V.C., 2003. Nonhydrostatic three-dimensional model for hydraulic flow simulation. I: Formulation and verification. Journal of Hydraulic Engineering 129, 196-205.

Landsberg, A., Chtchelkanova, A., Lind, C., Boris, J., Young, T., 1998. Fast3D user and programmer reference manual.

Lane, S.N., Bradbrook, K.F., Richards, K.S., Biron, P.A., Roy, A.G., 1999. The application of computational fluid dynamics to natural river channels: three-dimensional versus twodimensional approaches. Geomorphology 29, 1-20.

Lane, S.N., Richards, K.S., 1998. High resolution, two-dimensional spatial modelling of flow processes in a multi-thread channel. Hydrol. Process. 12, 1279-1298.

Lane, S.N., Richards, K.S., Chandler, J.H., 1995. Within-reach spatial patterns of process and channel adjustment. Hickin (ed.), River Geomorphology, John Wiley \& Sons Ltd.

Launder, B.E., Reece, G.J., Rodi, W., 1975. Progress in the development of a Reynolds-stress turbulence closure. Journal of Fluid Mechanics 68, 537-566.

Launder, B., Spalding, D.B., 1972. Lectures in Mathematical Models of Turbulence. Academic Press Inc.

Leclerc, M., 2005. Ecohydraulics: a new interdisciplinary frontier for CFD. Computational Fluid Dynamics: Applications in Environmental Hydraulics, pp.429-460.

Lipcius, R.N., Stockhausen, W.T., Eggleston, D.B., Marshall Jr, L.S., Hickey, B., 1997.

Hydrodynamic decoupling of recruitment, habitat quality and adult abundance in the Caribbean spiny lobster: source-sink dynamics? Marine and Freshwater Research 48, 807-816. 
Lundström, T.S., Brynjell-Rahkola, M., Ljung, A.-L., Hellström, J.G.I., Green, T.M., 2015. Evaluation of Guiding Device for Downstream Fish Migration with in-Field Particle Tracking Velocimetry and CFD. Journal of Applied Fluid Mechanics 8, 579-589.

Magnuson, J.J., Crowder, L.B., Medvick, P.A., 1979. Temperature as an ecological resource. American Zoologist 19, 331-343.

Mattiussi, C., 1997. An Analysis of Finite Volume, Finite Element, and Finite Difference Methods Using Some Concepts from Algebraic Topology. Journal of Computational Physics 133, 289 309.

Minh Duc, B., Wenka, T., Rodi, W., 1998. Depth-average numerical modeling of flow and sediment transport in the Elbe River, in: Proc 3rd Int Conf on Hydroscience and Engineering. Brandenburg University of Technology, Cottbus, Germany.

Moin, P., Mahesh, K., 1998. Direct numerical simulation: a tool in turbulence research. Annual review of fluid mechanics 30, 539-578.

Nimick, D.A., Gammons, C.H., Cleasby, T.E., Madison, J.P., Skaar, D., Brick, C.M., 2003. Diel cycles in dissolved metal concentrations in streams: occurrence and possible causes. Water Resources Research 39.

Oertel, M., Schlenkhoff, A., 2012. Crossbar block ramps: Flow regimes, energy dissipation, friction factors, and drag forces. Journal of Hydraulic Engineering 138, 440-448.

Olsen, N.R., 1994. SSIIM-A three dimensional numerical model for simulation of water and sediment flow. Hydrosoft-94, Porto Carras, Greece.

Onishi, Y., Wise, S.E., 1982. SERATRA: User's manual for the instream sediment-contaminant transport model. Technical Rep.

Orszag, S.A., 1970. Analytical theories of turbulence. Journal of Fluid Mechanics 41, 363-386.

Ozturk, I., Sarikaya, H.Z., Aydin, A.F., Demir, I., 1995. A simplified model for thermal discharges. Water Science and Technology 32, 183-191.

Papanicolaou, A.N., Elhakeem, M., Krallis, G., Prakash, S., Edinger, J., 2008. Sediment transport modeling review - current and future developments. Journal of Hydraulic Engineering 134, 114.

Plymesser, K., Cahoon, J., 2013. Concurrent Sessions C: Multi-Dimensional Modeling and Fish Passage Restoration-Modeling Fish Passage for American Shad in a Steeppass Fishway Using a Computational Fluid Dynamics (CFD) Model.

Poff, N.L., Allan, J.D., Bain, M.B., Karr, J.R., Prestegaard, K.L., Richter, B.D., Sparks, R.E., Stromberg, J.C., 1997. The natural flow regime. BioScience 47, 769-784.

Pope, S.B., 2000. Turbulent Flows. Cambridge University Press.

Ramadhyani, S., Patankar, S.V., 1980. Solution of the poisson equation: Comparison of the Galerkin and control-volume methods. Int. J. Numer. Meth. Engng. 15, 1395-1402. 
Riesterer, J., Wenka, T., Grafmüller, T., 2013. Comparison of hydraulic and morphological predictions of TelEMAC-3D/SISYPHE and SSIIM in curved laboratory channels. TUC 201393.

River2D, 2015. River2D. URL: http://www.river2d.ca/ (accessed 10.12.16).

Rodi, W., 1997. Comparison of LES and RANS calculations of the flow around bluff bodies. Journal of Wind Engineering and Industrial Aerodynamics, Proceedings of the 3rd International Colloqium on Bluff Body Aerodynamics and Applications 69-71, 55-75.

Rodi, W., 1993. Turbulence models and their application in hydraulics. CRC Press.

Rodriguez, J.F., Bombardelli, F.A., García, M.H., Frothingham, K.M., Rhoads, B.L., Abad, J.D., 2004. High-resolution numerical simulation of flow through a highly sinuous river reach. Water Resources Management 18, 177-199.

Rüther, N., Olsen, N.R., 2005. Three-dimensional modeling of sediment transport in a narrow 90 channel bend. Journal of Hydraulic Engineering 131, 917-920.

Sagaut, P., 2006. Large Eddy Simulation for Incompressible Flows: An Introduction. Springer Science \& Business Media.

Sawyer, A.H., Bayani Cardenas, M., Buttles, J., 2012. Hyporheic temperature dynamics and heat exchange near channel-spanning logs. Water Resources Research 48.

Sawyer, A.H., Bayani Cardenas, M., Buttles, J., 2011. Hyporheic exchange due to channel-spanning logs. Water Resources Research 47.

Shen, Y., Diplas, P., 2008. Application of two-and three-dimensional computational fluid dynamics models to complex ecological stream flows. Journal of Hydrology 348, 195-214.

Smagorinsky, J., 1963. General circulation experiments with the primitive equations. Mon. Wea. Rev. 91, 99-164.

Smith, G.D., 1985. Numerical Solution of Partial Differential Equations: Finite Difference Methods. Clarendon Press.

Stanford, J.A., Ward, J.V., 1988. The hyporheic habitat of river ecosystems.

Steffler, P., Blackburn, J., 2002. River 2D-Two-Dimensional Depth Averaged Model of River Hydrodynamics and Fish Habitat Introduction to Depth Averaged Modeling and User's.

TELEMAC, URL: http://www.opentelemac.org/ (accessed 3.24.16).

Thomas, W.A., McAnally Jr, W.H., 1985. User's Manual for the Generalized Computer Program System Open-Channel Flow and Sedimentation TABS-2. Main Text and Appendices A through O. DTIC Document.

Tonina, D., Buffington, J.M., 2007. Hyporheic exchange in gravel bed rivers with pool-riffle morphology: Laboratory experiments and three-dimensional modeling. Water Resources Research 43. 
Van Rijn, L.C. van, 1984. Sediment transport, part II: suspended load transport. Journal of hydraulic engineering 110, 1613-1641.

Versteeg, H.K., Malalasekera, W., 2007. An Introduction to Computational Fluid Dynamics: The Finite Volume Method. Pearson Education Limited.

Wallace, J.B., Webster, J.R., Meyer, J.L., 1995. Influence of log additions on physical and biotic characteristics of a mountain stream. Canadian Journal of Fisheries and Aquatic Sciences 52, 2120-2137.

Wang, P.-F., Chao, W., 2011. Numerical model for flow through submerged vegetation regions in a shallow lake. Journal of Hydrodynamics, Ser. B 23, 170-178.

Westrich, J.T., Berner, R.A., 1988. The effect of temperature on rates of sulfate reduction in marine sediments. Geomicrobiology Journal 6, 99-117.

Wilcox, D.C., 1991. A half century historical review of the k-omega model, in: 29th Aerospace Sciences Meeting. AIAA, pp. 91-0615.

Wilson, C., Yagci, O., Rauch, H.-P., Olsen, N.R.B., 2006. 3D numerical modelling of a willow vegetated river/floodplain system. Journal of hydrology 327, 13-21.

Wright, J.P., Flecker, A.S., 2004. Deforesting the riverscape: the effects of wood on fish diversity in a Venezuelan piedmont stream. Biological Conservation 120, 439-447.

Wu, J., You, S., Li, H., 2009. CFD-Based Prediction on Thermal Pollution, in: 2009 3rd International Conference on Bioinformatics and Biomedical Engineering.

Wu, W., Rodi, W., Wenka, T., 2000. 3D numerical modeling of flow and sediment transport in open channels. Journal of Hydraulic Engineering 126, 4-15.

Yakhot, V., Orszag, S.A., 1986. Renormalization group analysis of turbulence. I. Basic theory. J Sci Comput 1, 3-51.

Yao, W., Rutschmann, P., Bamal, S., 2014. Modeling of river velocity, temperature, bed deformation and its effects on rainbow trout (Oncorhynchus mykiss) habitat in Lees Ferry, Colorado River. International Journal of Environmental Research 8, 887-896.

Yao, W., Rutschmann, P., Sudeep, 2015. Three high flow experiment releases from Glen Canyon Dam on rainbow trout and flannelmouth sucker habitat in Colorado River. Ecological Engineering 75, 278-290.

Yoon, J.Y., Patel, V.C., 1996. Numerical model of turbulent flow over sand dune. Journal of Hydraulic Engineering 122, 10-18.

Zalewski, M., Janauer, G.A., Jolankai, G., 1997. Ecohydrology: a new paradigm for the sustainable use of aquatic resources. Ecohydrology. A New Paradigm for the Sustainable Use of Aquatic Resources. 
